\title{
X-ray Mapping of Wide Gap Brazed Bi-Metallic Composites
}

\author{
Paul Huggett ${ }^{1}$ and Richard Wuhrer ${ }^{2}$ \\ 1. Materials Solutions Pty Ltd, 27 Samphire Road, Canning Vale, WA, 6155, Australia \\ 2. University of Western Sydney, Advanced Materials Characterisation Facility (AMCF), Australia.
}

Traditional bi-metallic brazed composites require closely machined surfaces to allow capillary flow of the brazing alloy whilst promoting strong wetting of the bonding surfaces [1-55]. When producing wear resistant composites using white cast iron bonded to steel substrates, the high hardness of the white cast iron often requires expensive grinding to produce the tolerances required for standard brazing. A new process has been developed that permits wide gap brazing of white cast iron to steel without the need to machine either the white cast iron or the steel substrate. The new process utilizes a new brazing alloy that promotes excellent active wetting of the surfaces being brazed, and unlike standard brazing alloys, doesn't promote strong capillary flow. Due to the nature of the wide gap brazing without surface machining, it was necessary to determine if there were undesirable phases present at the braze interface, including oxides and other casting scale defects.

Castings typically have a range of undesirable phase present in the surface regions, including oxides and inorganic impurities such as moulding sand. When the bimetallic components are usually machined, these undesirable impurities are removed providing a clean surface for brazing.

Test samples were manufactured for analysis by placement of the brazing alloy between the cast face of a white cast iron block and a "black" steel bar. Black steel bar has the mill scale still present from the rolling process, so brazing the composite in this arrangement represents the worst case in respect to surface conditions. The white cast iron surface to be bonded was also significantly irregular, with an undulating surface in excess of 1 to $2 \mathrm{~mm}$ depth. The samples were then brazed in a small vacuum furnace at temperatures between 1150 to $1200 \mathrm{oC}$ with the furnace backfilled with a partial pressure of argon gas during the brazing phase of the heat treatment.

At the completion of the brazing cycle, samples were then sectioned and examined initially from a macro level to observe the braze region and ascertain the presence of any gross defects. Following visual analysis the samples were then sectioned for microstructural analysis, which included both optical and scanning electron microscopy (SEM). During the SEM analysis, $x$-ray mapping was used to further investigate the phases present and elemental distribution.

A typical macro of the wide gap brazed sample is shown in Fig 1. The macro shows a braze region in excess of $2 \mathrm{~mm}$ width, with some minor surface irregularities near the edges of the sample.

SEM analysis and x-ray mapping showed negligible oxygen present between the interfaces of the braze alloy and white cast iron, or the braze alloy and steel substrate. Typical SEM images from the wide gap brazed samples are shown in Fig. 2. The x-ray mapping also highlighted significant diffusion of alloying elements, such as chromium, which was not present in the starting braze alloy composition. The pseudo x-ray map for a typical wide gap brazed sample is shown in Fig. 3, and clearly shows the high level of chromium diffusion from the white cast iron through the braze alloy.

This paper will discuss some of the microstructural features observed with the wide gap brazed samples, and also review the diffusion of elements as a confirmation of the strong surface wetting developed during the process. Further process variables and improvements on the quality of the interface will also be presented as well as the final applications for these composites. 

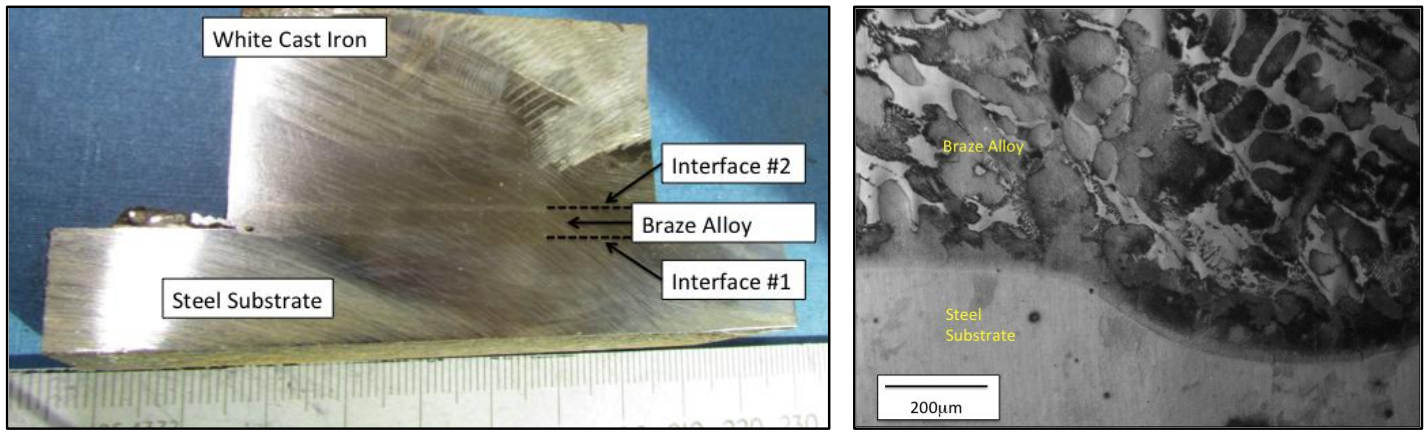

Fig 1: (a) Macro of wide gap brazed bi-metallia.composite and (b) higher magnification optical micrograph of bond between steel substrate and braze alloy.
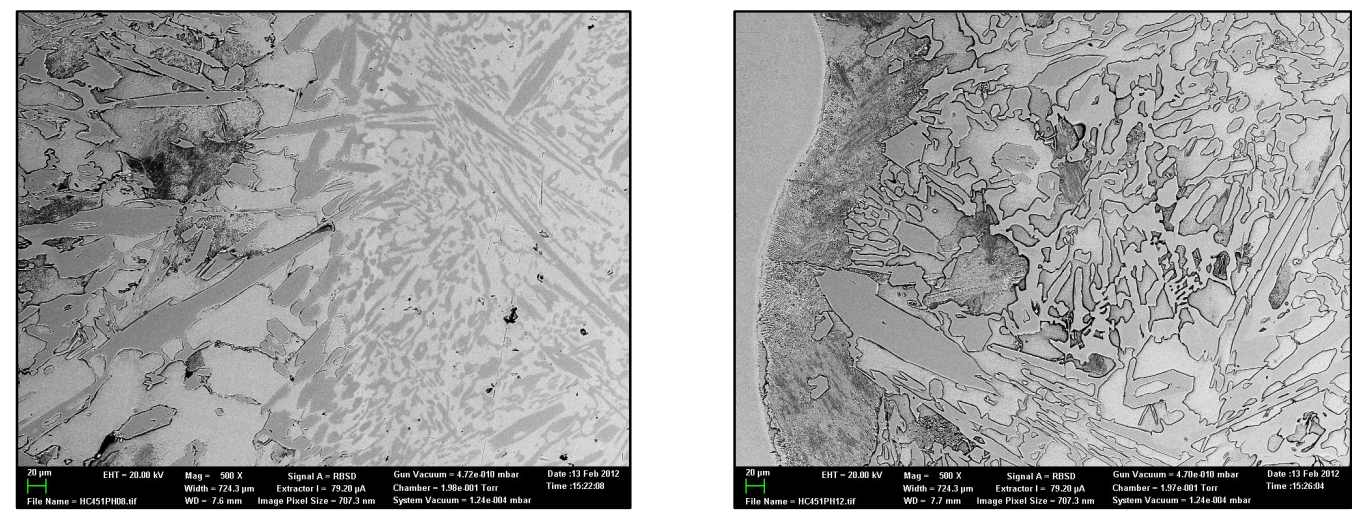

Fig. 2: (a) braze alloy (left) and white cast iron (right), and (b) steel substrate (left) and braze alloy (right).

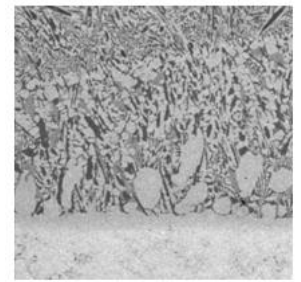

a.

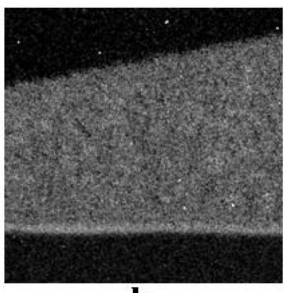

b.

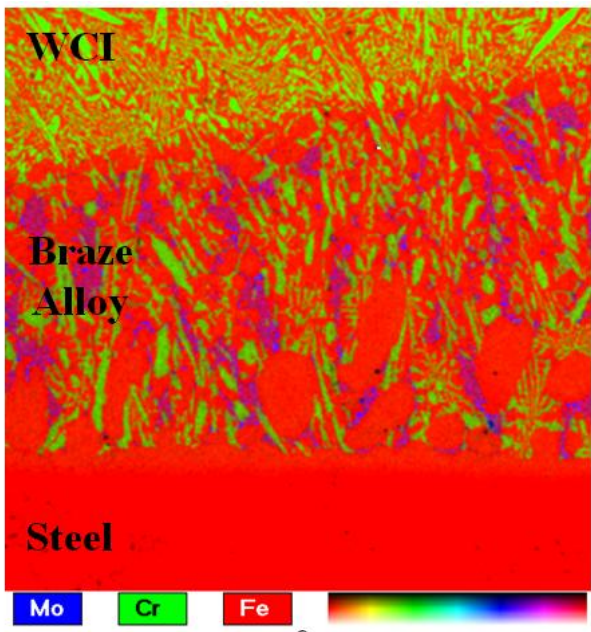

e.

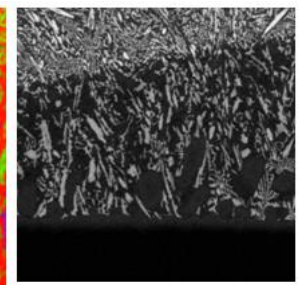

c.

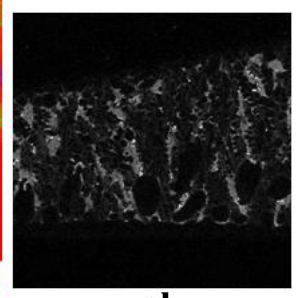

d.

Fig. 3: Wide gap brazed bimetallic sample. Quantitative x-ray map of a) Iron b) Manganese, c) Chromium, d) Molybdenum and e) pseudo coloured x-ray map. Despite braze alloy starting with zero chromium, joint has significant chromium via liquid/solid dissolution and diffusion

\section{References}

[1] G. Drach, "Application of Vacuum Brazing as a Metal Joining Technique”, Vacuum, vol 24, number 2, pp95-99, Feb 1974.

[2] M.J. Fletcher, "Vacuum Brazing", Engineering (London), vol 223, number 6, ppI-VIII, June 1983

[3] B. Edenhofer and J.W. Bouwman, "Vacuum Heat Treatment", Steel Heat Treatment Handbook, pp483$525,1997$.

[4] T. Yoshida and H. Ohmura, "Dissolution and Deposit of Base Metal in Dissimilar Carbon Steel Brazing", Welding Journal, vol 59, number 10, pp278-282, October 1980. 